\title{
CONDIÇÕES DE COMERCIALIZAÇÃO E QUALIDADE DE QUEIJOS MINAS FRESCAIS EM FEIRAS LIVRES E MERCADO MUNICIPAL DE CAMPO GRANDE, MS
}

\section{Conditions of sale and quality of Minas Frescal cheeses in street fairs and municipal market of Campo Grande, MS}

\author{
Luciane Nunes Ribeiro da Silva ${ }^{l}$, Marcela de Rezende Costa ${ }^{1 *}$
}

\begin{abstract}
RESUMO
As pessoas buscam em feiras livres e mercados municipais uma variedade de mercadorias locais e com apelo artesanal e/ou natural, dentre elas os queijos como o Minas Frescal. Cuidados com produção, manipulação e exposição dos alimentos devem ser tomados para garantir a qualidade e preservar a saúde da população. Este trabalho avaliou parâmetros físico-químicos e microbiológicos de queijos artesanais Minas Frescal de feiras livres e do mercado municipal de Campo Grande, MS, bem como suas condições de manipulação, exposição e armazenamento. Nos aspectos de estrutura da banca, temperatura e condições de exposição dos queijos, e presença de coletor de lixo e de lavatório, $80 \%$ das bancas estavam inadequadas e $90 \%$ com relação a uso de equipamento de proteção individual, higienização das mãos e dos utensílios. A maioria dos queijos estavam conforme os padrões da legislação de Identidade e Qualidade do Queijo Minas Frescal quanto a parâmetros físico-químicos, apenas uma amostra estava com teor de umidade inferior ao exigido. Quanto às avaliações microbiológicas, $100 \%$ das amostras estavam acima do limite de coliformes a $45{ }^{\circ} \mathrm{C}$ e $30 \%$ de Staphylococcus aureus coagulase positiva. Nenhuma amostra apresentou Salmonella sp. Porém, foi detectada a presença de Listeria monocytogenes em 20\% delas. Os resultados indicam falta de controle higiênico-sanitário sobre os queijos Minas Frescais vendidos nas feiras livres de Campo Grande, MS, apresentando inclusive, em alguns, a presença de bactérias patogênicas, um sério risco à saúde do consumidor.
\end{abstract}

1 Universidade Federal de Mato Grosso do Sul, Faculdade de Ciências Farmacêuticas, Alimentos e Nutrição, Cidade Universitária, Av. Costa e Silva, s/n, Pioneiros, 79070-900, Campo Grande, MS, Brasil. E-mail: marcela.rezende@ufms.br

* Autor para correspondência

Recebido / Received: 14/08/2020

Aprovado / Approved: 18/09/2020 
Palavras-chave: queijo artesanal; doenças transmitidas por alimentos; segurança de alimentos.

\begin{abstract}
Customers search at street fairs and municipal markets for a variety of local goods, with artisanal and/or natural appeal, among them cheeses such as Minas Frescal. Care must be taken with production, handling, and exposure of food to guarantee the quality and preserve the health of the population. This research evaluated the physical-chemical and microbiological parameters of artisanal Minas Frescal cheeses from street fairs and the municipal market of Campo Grande, MS, as well as their handling, exposure, and storage conditions. In terms of the stand structure, cheese temperature and exposure conditions, and the presence of garbage collector and washbasin, $80 \%$ of the stalls were inadequate and $90 \%$ concerning the use of personal protective equipment and hand and utensil hygiene procedures. Most cheeses were in accordance with the legislation of Minas Frescal Standard of Identity and Quality, regarding physical-chemical parameters, only one sample had moisture content lower than that required. As for the microbiological assessments, $100 \%$ of the samples were above the limit of coliforms at $45{ }^{\circ} \mathrm{C}$ and $30 \%$ of Staphylococcus aureus coagulase positive. No sample presented Salmonella sp. However, the presence of Listeria monocytogenes was detected in $20 \%$ of them. The results indicate a lack of hygienic-sanitary control over Minas Frescal cheeses sold in street markets in Campo Grande, MS, even presenting, in some samples, the presence of pathogenic bacteria, a serious risk to consumer health.
\end{abstract}

Keywords: artisanal cheese; foodborne diseases; food safety.

\section{INTRODUÇÃO}

Feiras livres e mercados municipais são mercados públicos populares que tem um aglomerado de pessoas em busca de variedades de mercadorias e diferenciação nos preços. Com sua rica diversidade cultural e biológica, no Brasil as feiras livres assumem diferentes funções e aspectos sociais e econômicos. Sua modalidade é o comércio varejista ao ar livre no qual regularmente gêneros alimentícios e produtos básicos são oferecidos (MASCARENHAS; DOLZANI, 2008).

Em Campo Grande, MS, além das diversas feiras livres, há o Mercado Municipal Antônio Valente, conhecido com Mercadão. Inaugurado em agosto de 1958, originou-se de uma feira livre que ocorria ao longo dos trilhos da Companhia Noroeste (CAMPO GRANDE,
20-?). Dentre os produtos de origem animal comercializados nesses locais, os queijos são comuns. É um produto que se destaca dentre os derivados lácteos pelo alto teor de proteína e outros nutrientes e, com o desenvolvimento da tecnologia na sua produção surgiram em nível nacional muitas variedades, sendo algumas de expressão regional (BORGES et al., 2003).

Os queijos frescos apresentam maior susceptibilidade do que os maturados a contaminações e desenvolvimento microbianos, que é possível ocorrer a partir do leite utilizado como matéria-prima ou por contaminações durante ou após o processamento, especialmente quando é mantido e/ou manipulado em condições inadequadas, como é possível de ocorrer especialmente em comércios de rua como as feiras. As 
contaminações, em poucos dias, tornam o queijo inaceitável ou até mesmo impróprio para o consumo (ROCHA et al., 2006).

Os queijos Minas Frescais produzidos artesanalmente e vendidos em feiras, normalmente, são feitos a partir do leite cru. Seu método de fabricação possui diversas etapas, mas nenhum tratamento térmico para eliminar possíveis microrganismos patogênicos e a microbiota deteriorante, o que o torna um dos alimentos mais susceptíveis a contaminações (ALMEIDA FILHO; NADER FILHO, 2000; GONTIJO; BRANCO, 1998). Sendo assim, as pessoas ficam suscetíveis a doenças transmitidas por esse alimento, principalmente por queijos frescos. Dessa forma, é de suma importância aplicar as boas práticas de fabricação e de manipulação (BUYSER et al., 2001; KOUSTA et al., 2010).

De acordo com a ANVISA (BRASIL, 1993), as Boas Práticas de Fabricação (BPF) abrangem um conjunto de medidas que devem ser adotadas pelas indústrias de alimentos e pelos serviços de alimentação, a fim de garantir a qualidade sanitária e a conformidade dos alimentos através do regulamento técnico. Já as Boas Práticas de Manipulação (BPM) são práticas de higiene que devem ser respeitadas pelos manipuladores, desde a escolha da matéria prima que será utilizado em preparo de alimento até a venda de produtos para o consumidor. O principal objetivo delas é evitar a ocorrência de doenças provocadas pelo consumo de alimentos contaminados, as Doenças Transmitidas por Alimentos (DTAs), que são causadas por agentes etiológicos principalmente microrganismos e suas toxinas (HOBBS; ROBERTS, 1999).

A ausência de cuidados, incluindo as BPFs e as BPMs, na elaboração, manipulação, exposição e armazenamento dos queijos pode causar contaminações química, física e, principalmente, microbiológica. Assim, a verificação das condições dos alimentos disponíveis em mercados populares, como feiras e mercados municipais, é fundamental para preservar a saúde da população. Desta forma, o objetivo deste trabalho foi avaliar a qualidade microbiológica e físico-química dos queijos Minas Frescais artesanais comercializados em locais de comércio público popular de Campo Grande, MS, bem como as condições de manipulação, exposição e armazenamento dos queijos nos locais de venda, além de comparar as características encontradas com os parâmetros e condições exigidos pela legislação brasileira, traçando, assim, um perfil da qualidade sanitária dos queijos encontrados nesses locais.

\section{MATERIAL E MÉTODOS}

Os queijos Minas Frescais artesanais foram comprados em nove feiras livres e no mercado municipal de Campo Grande, MS, sendo escolhida aleatoriamente uma banca de cada local na qual foi adquirido um queijo, totalizando 10 amostras. As amostras foram acondicionadas em caixa térmica com gelo para o transporte e, em seguida, refrigeradas até serem analisadas, em no máximo 12 horas após a compra, nos laboratórios de uma empresa privada que cedeu material e local para a realização das análises.

$\mathrm{Na}$ compra dos queijos, para cada local foi preenchido um formulário onde foram considerados os seguintes aspectos observados no momento da compra: condições sanitárias e estrutura do local, equipamentos e utensílios, higiene do manipulador, forma de manipulação, uso de uniforme, máscara e touca, local de exposição e armazenamento do queijo.

Foram realizadas análises físicoquímicas de teor de umidade, $\mathrm{pH}$ e acidez titulável (ZENEBON et al., 2008) e microbiológicas de contagens de coliformes a $45^{\circ} \mathrm{C}$, método do Número Mais Provável (NMP), e de Staphylococcus aureus coagulase positiva, método direto em placas 
(KORNACKI et al., 2015) e de detecção de Salmonella sp., por meio de kits de teste GeneQuence $^{\circledR}$, e de Listeria monocytogenes, por meio de kits de teste Reveal ${ }^{\circledR} 2.0$ (Neogen). Os resultados foram avaliados de acordo com a legislação brasileira sobre Boas Práticas de Manipulação de Alimentos (BRASIL, 1993, 2004b), Identidade e Qualidade de Queijos (BRASIL, 1996, 1997, 2004a, 2020), Critérios Microbiológicos para Avaliação de Alimentos (BRASIL, 2001), e legislação de Campo Grande (CAMPO GRANDE, 2014) sobre o funcionamento de feiras livres.

\section{RESULTADOS E DISCUSSÃO}

\section{Estrutura da banca}

As observações feitas nos dez locais onde ocorreram as compras dos queijos analisados neste trabalho estão resumidas no Quadro 1. No quesito estrutura da banca, 80\% estavam em boas condições, organizadas e cobertas, enquanto o restante estava em más condições, desorganizadas e descobertas. As bancas de estruturas de madeiras e metálicas estavam sempre cobertas por um material de PVC ou lonas e sua estrutura metálica, algumas pintadas e outras com as pinturas, já gastas. As bancas de metal sofrem oxidação e podem causar contaminação nos alimentos.

A lei complementar $n^{\circ} 223 / 2014$ da Câmara Municipal de Campo Grande, MS (CAMPO GRANDE, 2014) exige que as bancas devem possuir toldos de lona (uma cobertura) que abriguem as mercadorias dos raios solares, das chuvas e serenos. A resolução RDC no 216/2004 da ANVISA (BRASIL, 2004b), que dispõe sobre o Regulamento Técnico de Boas Práticas para Serviços de Alimentação, determina que os equipamentos, móveis e utensílios que entram em contato com alimentos devem ser de materiais que não transmitam substâncias tóxicas, odores, nem sabores aos mesmos.
Além disso, devem ser mantidos em adequado estado de conservação e ser resistentes à corrosão e a repetidas operações de limpeza e desinfecção.

Abreu; Cabral (2005), relatou que bancas que possuem superfícies irregulares, como as de madeira e cimento, dificultam a higienização, tornando-as inadequadas, pois acumulam sujidades e, como consequência, pode ocorrer contaminação por microrganismos. Castro et al. (2011) observaram que a ardósia tem uma fácil higienização e superfície uniforme, assim podem atender os critérios da ANVISA (BRASIL, 1993, 2004b).

\section{Temperatura e forma de exposição dos queijos}

A bancas visitadas nessa pesquisa vendiam os queijos embalados em plástico transparente, alguns deles apresentavam sinérese (expulsão de soro do queijo) e o excesso acabava escorrendo sobre a bancada, o que poderia contribuir para proliferação microbiana. Dos 10 locais, em 8 os queijos estavam sem refrigeração e em apenas 2 eram mantidos em câmara de refrigeração. Alguns dos mantidos sem refrigeração estavam dentro de caixas de isopor com gelo e outros em caixas térmicas sem gelo. Mas, em sua maioria, eram vendidos sob o balcão em temperatura ambiente. $\mathrm{O}$ funcionamento das feiras, em geral, é das 16 até as 22 horas, assim os queijos ficariam nessas condições por pelo menos 6 horas, favorecendo o desenvolvimento microbiano e a possibilidade de ocorrência de doenças de origem alimentar.

Condições similares foram observadas por Fava et al. (2012), em uma feira agropecuária no Rio Grande do Sul, onde encontraram queijos tipo Colonial expostos para comercialização em temperatura ambiente em 6 dos 12 locais analisados (50\%), e por Rezende et al. (2010), em Uberlândia, 


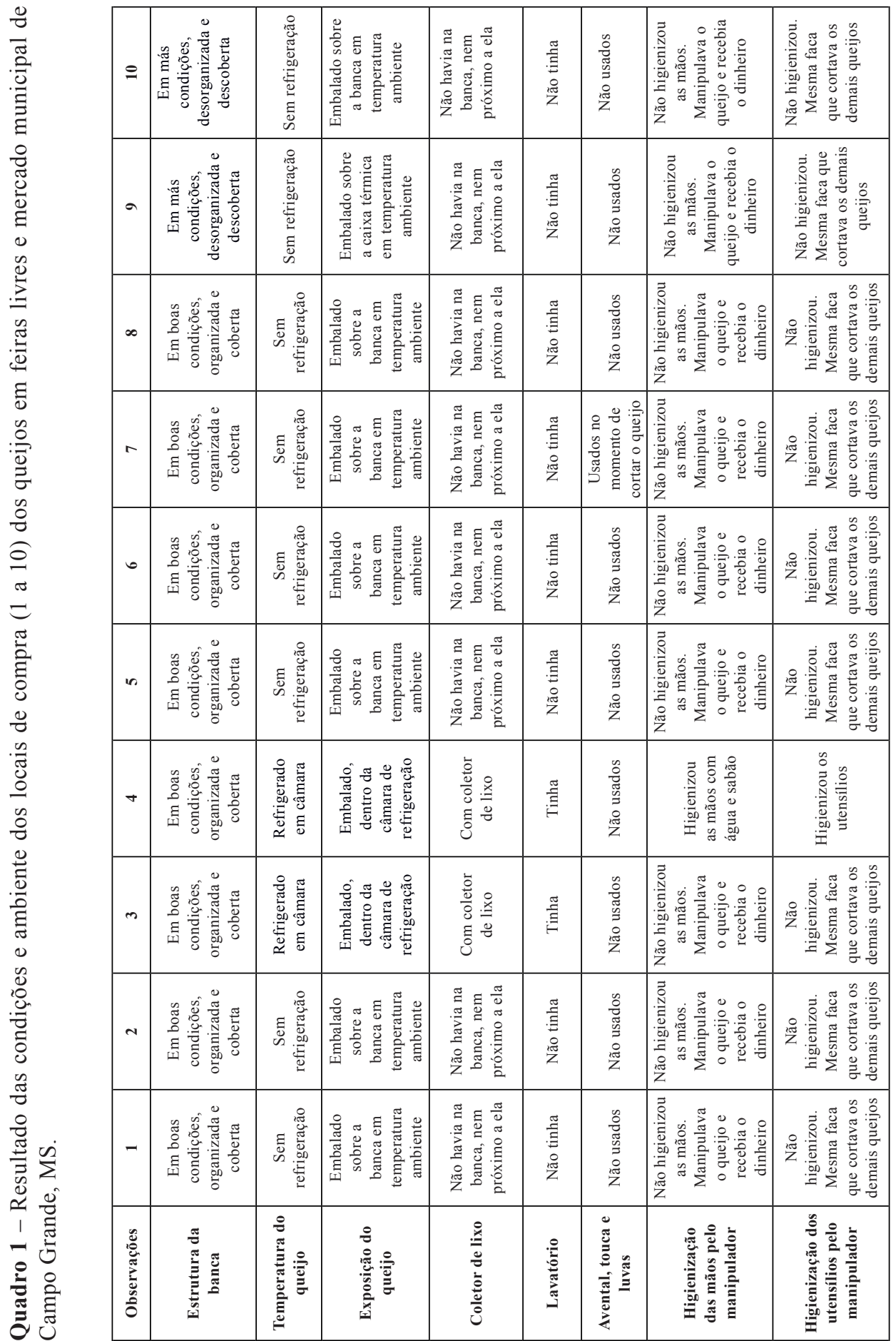


MG, onde observou queijos Minas artesanais expostos para venda em bancas de madeiras e em temperatura ambiente.

No entanto, essas condições desfavoráveis não são encontradas exclusivamente em feiras livres e mercados municipais. O Programa de Análise de Produtos feito pelo Instituto Nacional de Metrologia, Qualidade e Tecnologia (INMETRO) analisou em 2005 queijos dos tipos Minas Frescal e Padrão de 21 marcas comerciais em sete estados brasileiros e observou que durante a aquisição das amostras $48 \%$ estavam em temperatura acima da recomendada pela legislação (INMETRO, 2006). De acordo com o MAPA, esses tipos de queijos devem ser acondicionados para a venda embalados e em temperaturas de até $8^{\circ} \mathrm{C}$ para o Minas Frescal (BRASIL, 1997) e de até $12^{\circ} \mathrm{C}$ para o Minas Padrão (BRASIL, 2020).

\section{Coletores de lixo e lavatórios}

Foi observado que apenas dois locais (o mercado municipal e a feira central), dos dez avaliados, possuíam coletores de lixo e lavatórios para as mãos. Esses locais, talvez por serem locais físicos permanentes, estavam com o lixo e lixeiras de maneira adequada, além de apresentarem ambientes limpos e organizados. Não possuir coletores de lixo, facilita o descarte do lixo em locais e de maneira inadequada, exposto as pessoas e os alimentos a esses resíduos gerados nas feiras. Além disso, Pradella; Basso (2015) relatam que a falta de lavatórios adequados traz como consequência dificuldade na higienização dos manipuladores, equipamentos e utensílios, o que também contribui para a contaminação dos alimentos.

A lei municipal complementar $\mathrm{n}^{\circ}$ $223 / 2014$ obriga em feiras livres as bancas, barracas, boxes, reboques ou veículos adaptados possuírem coletores de lixo, de dimensões proporcionais às suas necessidades, devendo o lixo ser acondicionado em sacos plásticos (CAMPO GRANDE, 2014). De acordo com a RDC no 216/2004 (BRASIL, 2004b), os coletores dos resíduos devem ser dotados de tampa e acionados sem contato manual.

A falta de lavatórios nas bancas de feiras é um problema crítico devido à ausência de infraestrutura nos locais. No trabalho do Carvalho et al. (2017), realizado em feiras livres de Natal, RN, foi constatado que não havia lavatório de qualquer tipo nos locais avaliados. Já Lundgren et al. (2009), João Pessoa, PB, observou que 16,4\% das barracas não dispunham de lavatório para a lavagem das mãos e que, nas que tinham, o lavatório também servia para a lavagem de equipamentos e utensílios.

A lei municipal complementar $n^{\circ}$ 223/2014 não é clara quanto à exigência de lavatórios em cada barraca, apenas diz que as mesmas devem fazer o uso de instalações elétricas ou hidráulicas de acordo às normas a serem definidas pelo órgão municipal competente e um representante da feira em questão. Porém, essa lei obriga o executivo municipal a dotar a feira de infraestrutura mínima, com sanitários químicos onde houver necessidade, e, pelo menos, um ponto de hidráulica para uso coletivo (CAMPO GRANDE, 2014). De acordo com a RDC n ${ }^{\circ} 216 / 2004$, devem existir lavatórios exclusivos para a higiene das mãos na área de manipulação de alimentos. Os lavatórios devem possuir sabonete líquido inodoro antisséptico ou sabonete líquido inodoro e produto antisséptico, toalhas de papel não reciclado ou outro sistema higiênico e seguro de secagem das mãos e coletor de papel, acionado sem contato manual (BRASIL, 2004b).

\section{Equipamentos de proteção individuais}

Dentre as feiras e mercado municipal apenas em um local havia a utilização de 
touca, avental e luvas pelo manipulador dos alimentos. Resultado similar aos de Pradella; Basso (2015), que observaram que em 92\% das bancas de alimentos, em feiras livres de Santa Maria, RS, avaliadas os atendentes não utilizavam toucas e jaleco e $100 \%$ não utilizam luvas. De acordo com Cavalcanti et al. (2014), não é praticado com frequência ou integralmente o uso de equipamentos individuais e boas práticas de manipulação de alimentos nas feiras livres.

A lei municipal complementar $n^{\circ}$ $223 / 2014$ determina que durante as horas em que exercerem o seu comércio os feirantes deverão usar gorros ou bonés, jalecos e crachás de identificação, observando o asseio, tanto no vestuário, utensílios utilizados, bem como no espaço que utiliza nas feiras livres (CAMPO GRANDE, 2014). De maneira similar, a RDC no $216 / 2004$ diz que os manipuladores devem ter asseio pessoal, apresentando-se com uniformes compatíveis à atividade, conservados e limpos. Além disso, devem usar cabelos presos e protegidos por redes, toucas ou outro acessório apropriado para esse fim, não sendo permitido o uso de barba. As unhas devem estar curtas e sem esmalte ou base. Durante a manipulação, devem ser retirados todos os objetos de adorno pessoal e a maquiagem (BRASIL, 2004b).

\section{Higienização das mãos e dos utensílios}

Como já visto, apenas dois locais possuíam lavatórios nas barracas, dificultando a higienização das mãos e utensílios pelos atendentes. Partindo dessa situação já problemática, em apenas uma banca das feiras o feirante higienizou os utensílios e as mãos antes de manipular o produto para o consumidor. Havia bancas que vendiam queijos fracionados e outras os vendiam inteiros e naquelas que cortavam o produto no momento da venda, em geral, o atendente utilizava uma faca sem higienizá-la e ainda usava o mesmo utensílio para cortar outros queijos em seguida. Em um dos locais, o feirante deixava a faca suja exposta sobre a banca. Ainda foi observado que, em geral, a mesma pessoa manipulava os queijos e o dinheiro e que o manipulador dos alimentos não higienizava as mãos ao trocar de função na banca.

Situações parecidas foram descritas em diversos trabalhos realizados em feiras livres brasileiras. Tinoco et al. (2009), em Seropédica, RJ, verificaram que apenas 13\% das bancas avaliadas em feira livres possuíam pias exclusivas para a lavagem das mãos e $70,83 \%$ dos atendentes não lavavam as mãos para manipular os alimentos. Rezende et al. (2010) relatou que quando os feirantes cortavam os queijos não havia nenhuma higienização na faca utilizada. Silva et al. (2008), Freire et al. (2011), Pinto et al. (2012) e Holanda et al. (2013) observaram em feiras livres de diferentes localidades no Brasil que muitos atendentes utilizavam um recipiente único de água para enxaguar os utensílios entre a manipulação ou corte de um queijo e outro.

Segundo Zandonadi et al. (2007), as mãos entram em contato com o ambiente, indivíduos, alimentos, equipamento e utensílios. Além disso, o manipulador pode espirrar ou estar com ferimentos nas mãos, que também são fontes de contaminação. Assim, o estado de saúde do manipulador, o uso de equipamentos de proteção e a higienização adequada de mãos e utensílios são muito importantes para prevenir a transmissão de microrganismos infecciosos.

\section{Análises laboratoriais}

Quanto a parâmetros físico-químicos quantitativos, a legislação brasileira só classifica os queijos com relação aos seus teores de umidade e de gordura no extrato seco (GES) (BRASIL, 1996). O queijo Minas 
Frescal é classificado como semi-gordo $(25,0$ a $44,9 \%$ de GES) e de muito alta umidade (igual ou superior a 55\%) (BRASIL, 2004a), enquanto o Minas Padrão seria considerado um queijo semi-gordo a gordo (45,0 a 59,9\% de GES) e de média umidade (entre 36,0 e 45,9\%) (BRASIL, 2020). Os resultados obtidos nesse trabalho (Tabela 1) indicam que apenas um dos queijos avaliados estava fora do padrão de umidade do Minas Frescal, sendo classificado como de alta umidade (entre 46,0 e $54,9 \%)$.

Alves (2013), em seu trabalho em Volta Redonda, RJ, observou que em apenas 40\% dos boxes avaliados nas feiras apresentaram $100 \%$ das amostras dentro do valor de umidade exigido na legislação (acima de 55\%). Já Ricardo et al. (2011) observaram que em Londrina, PR, apenas 50\% das amostras analisadas estavam conformes nesse parâmetro. Os autores ressaltaram que essa oscilação nos teores de umidade ocorre pela falta de padronização na composição do leite e na salga, no corte, na mexedura e no armazenamento do queijo.

Com relação à acidez, a maioria $(60 \%)$ dos queijos avaliados encontravam-se nas faixas de 0,10 a 0,30 g/ $100 \mathrm{~g}$ de ácido lático.
Já com relação ao $\mathrm{pH}$, a variação foi maior, $40 \%$ estavam na faixa de 5,0 a 5,5, 20\% de 5,6 a 6,0 e $40 \%$ de 6,1 a 6,5 . Valores similares aos trabalhos de Barbosa et al. (2019), que encontraram acidez de $0,16 \%$ a $0,22 \%$, e de Buriti et al. (2005) que observaram que nos queijos Minas Frescais armazenados durante 21 dias a uma temperatura de $8{ }^{\circ} \mathrm{C}$ o $\mathrm{pH}$ diminuiu de 6,16 para 5,38. Já Souza et al. (2017) obtiveram valores de $\mathrm{pH}$ entre 4,98 e 7,14 .

Uma acidez muito alta pode prejudicar o aspecto sensorial e descaracterizar os queijos. Para Silva (2005) a faixa de $\mathrm{pH}$ ideal para queijos Minas Frescais está entre 5,0 e 5,3. Queijos com pH mais elevado apresentam menor vida de prateleira, já que um pH mais próximo da neutralidade favorece a multiplicação de microrganismos (SOUZA et al., 2017).

Com relação aos resultados microbiológicos (Tabela 2), as contagens de coliformes a $45^{\circ} \mathrm{C}$ (termotolerantes) estavam acima do limite da legislação para todas as amostras. Já com relação à Salmonela, nenhuma das amostras mostrou presença dessa bactéria, estando conforme a exigência da legislação.

Tabela 1 - Resultados das análises físico-químicas de queijos Minas Frescais coletados em feiras livres e mercado municipal de Campo Grande, MS

\begin{tabular}{ccccc}
\hline Parâmetro & $\begin{array}{c}\text { Faixas de } \\
\text { valores }\end{array}$ & $\begin{array}{c}\text { Número de } \\
\text { amostras }\end{array}$ & $\begin{array}{c}\text { Média } \pm \\
\text { Desvio-padrão }\end{array}$ & Variação \\
\hline Umidade & $46,0-54,9$ & 1 & $57,10 \pm 3,13$ & $52,16-64,17$ \\
$(\mathrm{~g} / 100 \mathrm{~g})$ & $\geq 55,0$ & 9 & & \\
\hline Acidez & $0,10-0,30$ & 6 & & \\
$(\mathrm{~g}$ de ácido láctico/ & $0,31-0,60$ & 3 & & \\
100 g de queijo $)$ & $0,61-0,90$ & 1 & $5,13-0,90$ \\
\hline & $5,00-5,50$ & 4 & & $5,10-6,30$ \\
$\mathrm{pH}$ & $5,60-6,00$ & 2 & & \\
& $6,10-6,50$ & 4 & & \\
\hline
\end{tabular}


Dentre as enterobactérias encontramos coliformes termotolerantes e Salmonella sp. e a presença delas fora dos limites previstos indicaria uma má condição higiênicosanitária do produto. Além disso, algumas enterobactérias como cepas de Escherichia coli (coliforme termotolerante) e de Salmonela podem ser patogênicas para o ser humano, causando doenças de origem alimentar (FRANCO; LANDGRAF, 2008).

Ferreira et al. (2011) avaliaram amostras de queijo Minas Frescal obtidas em feiras livres de Uberlândia, MG, e 80\% estavam com a contagem de coliformes termotolerantes superior ao permitido. Sousa et al. (2020) também não encontraram a presença de Salmonella em queijos frescais adquiridos em feiras livres de Rio Verde, GO. Almeida et al. (2012) e Melo et al. (2013) relataram que a ausência de Salmonella nesse tipo de produto pode ser justificada pela sua baixa competitividade em relação a bactérias do grupo coliformes e Staphylococcus.

Abreu et al. (2011), em uma pesquisa em Santo André, SP, observaram que as mãos de manipuladores de alimentos apresentavam um alto índice de contaminação por coliformes termotolerantes, sendo um dos principais veículos de contaminação por esses microrganismos em alimentos. Outro veículo de contaminação por enterobactérias é a água. Porto et al. (2011) realizaram um estudo em redes de fast food em Recife, PE, para avaliar a água usada na preparação de alimentos e consumo direto e constataram que $11,46 \%$ das amostras apresentaram contaminação por coliformes totais e $1,04 \%$ por coliformes termotolerantes.

A contagem de Staphylococcus aureus coagulase positiva nos queijos avaliados nesse trabalho resultou em sete amostras dentro e três fora do limite da legislação (Tabela 2). Amorim et al. (2014) encontraram que 100\% das amostras de queijos artesanais informais continham elevadas contagens de $S$. aureus coagulase positivas, variando de $2,5 \times 10^{6}$ a $1,75 \times 10^{7} \mathrm{UFC} / \mathrm{g}$. Na pesquisa de Dias et al. (2016) apenas 30\% dos queijos estavam dentro do limite $\left(\leq 5,0 \times 10^{2} \mathrm{UFC} / \mathrm{g}\right)$ de acordo com a legislação (BRASIL, 2001).

Bannerman (2003) e Rocha et al. (2006) afirmaram que o queijo é um dos principais alimentos relacionados com intoxicação alimentar e que o microrganismo mais importante responsável por isso é o $S$. aureus, relacionado principalmente à higiene inadequada dos manipuladores, especialmente a falta de lavagem das mãos.

Com relação à Listeria monocytogenes foi constatada sua presença em duas das 10

Tabela 2 - Resultados das análises microbiológicas de queijos Minas Frescais coletados em feiras livres e no mercado municipal de Campo Grande, MS.

\begin{tabular}{lccc}
\hline Bactérias & $\begin{array}{c}\text { Limites da } \\
\text { legislação* }\end{array}$ & $\begin{array}{c}\text { Amostras (n) } \\
\text { dentro do limite }\end{array}$ & $\begin{array}{c}\text { Amostras (n) } \\
\text { acima do limite }\end{array}$ \\
\hline Coliformes a $45^{\circ} \mathrm{C}(\mathrm{NMP} / \mathrm{g})$ & $\leq 5,0 \times 10^{2}$ & 0 & 10 \\
$\begin{array}{l}\text { Staphylococcus coagulase positiva } \\
\text { (UFC/g) }\end{array}$ & $\leq 5,0 \times 10^{2}$ & 7 & 3 \\
Listeria monocytogenes $(\mathrm{em} 25 \mathrm{~g})$ & Ausência & 8 & 2 \\
Salmonella sp. $(\mathrm{em} 25 \mathrm{~g})$ & Ausência & 10 & 0 \\
\hline
\end{tabular}

* $\mathrm{RDC}^{\circ}{ }^{\circ}$ 12, de 02 de janeiro de 2001 da ANVISA (BRASIL, 2001). 
amostras avaliadas, tornando-as inaceitáveis ao consumo de acordo com a legislação (BRASIL, 2001). Essa incidência foi maior do que as encontradas em outros trabalhos. No estudo de Apolinário et al. (2014), foram analisadas 31 amostras e em 9,6\% delas verificou-se a presença de Listeria monocytogenes. Raimundo (2013) avaliou 165 amostras de queijos meia cura obtidos em feira livres de São Paulo, SP, e apenas 3 delas evidenciaram a presença de L. monocytogenes.

A falta de cuidado no uso das Boas Práticas de Fabricação e de Manipulação no processamento do queijo Minas Frescal, fabricado de forma artesanal, coloca-o em condições sujeitas à contaminação e proliferação de microrganismos, podendo prejudicar sua qualidade e afetar a saúde do consumidor. Caccamo et al. (2004) afirmou que é muito comum encontrar "furinhos" (ou olhaduras) nos queijos, e que os consumidores de uma maneira geral remetem isso a queijos de boa qualidade sensorial. Nesse trabalho, em algumas das bancas foram adquiridos queijos como o visualizado na Figura 1. As olhaduras podem ter origens mecânicas, quando em pequenas quantidades e não uniformes na massa. Entretanto, essa aparência rendada do queijo das fotos é típica de contaminação e proliferação de coliformes termotolerantes, que produzem gás e levam à formação dessas olhaduras pequenas distribuídas uniformemente por toda a peça, causando o estufamento do tipo precoce no queijo (FURTADO, 2017).

Na banca onde esse queijo foi adquirido, os queijos eram mantidos em uma caixa térmica aparentemente não higienizada, sendo que alguns queijos estavam expostos em cima da caixa em temperatura ambiente. Os resultados microbiológicos desse queijo foram: acima do limite para coliformes termotolerantes, dentro do limite para Staphylococcus aureus coagulase positiva, presença de L. monocytogenes (inaceitável) e ausência de Salmonella, de acordo com a RDC $n^{\circ} 12 / 2001$ da ANVISA (BRASIL, 2001), relacionados a condições higiênicosanitárias insatisfatórias, que não garantem boas práticas de manipulação, armazenamento e comercialização do produto, um risco a saúde do consumidor.

Garantir alimentos seguros nas feiras depende, em grande parte, da qualidade original do produto, do comportamento adequado dos feirantes nas atividades, da existência de
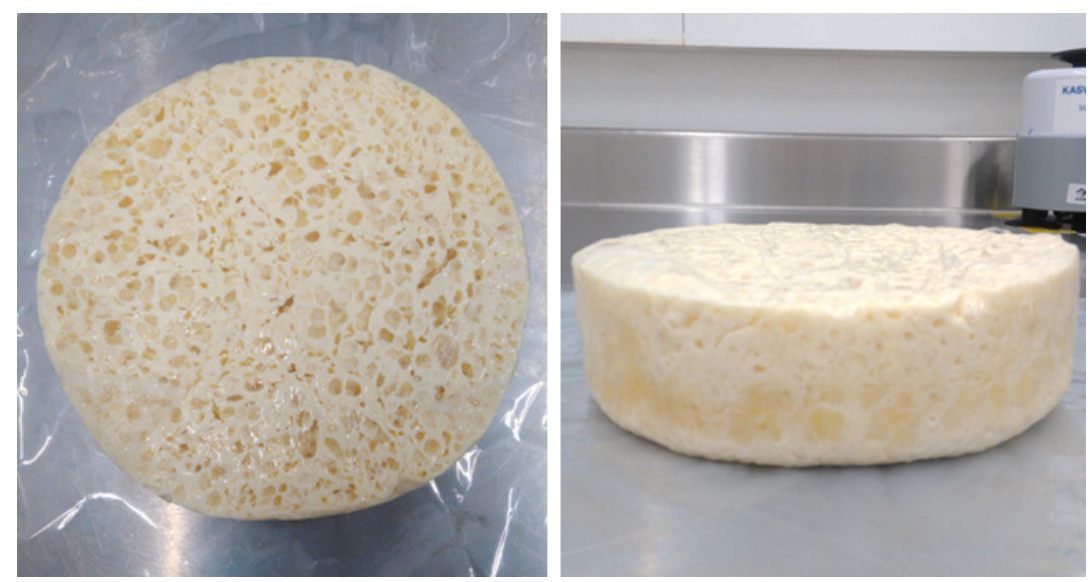

Figura 1 - Queijo Minas Frescal adquirido em uma feira livre de Campo Grande, MS. 
infraestrutura básica oferecida pela prefeitura e do uso de equipamentos específicos, bem como da fiscalização governamental periódica efetiva para orientar e verificar essas condições. Assim, capacitação, orientação e fiscalização adequadas podem juntas ser uma forma de auxiliar no controle de qualidade e garantir a segurança dos alimentos comercializados.

\section{CONCLUSÕES}

A maioria das bancas de venda de queijos artesanais dos mercados livres de Campo Grande, MS, avaliadas nesse trabalho, não apresentam condições adequadas de infraestrutura física e de capacitação dos atendentes quanto à manipulação de alimentos, não oferecendo a garantia de um produto seguro ao consumidor. Os queijos Minas Frescal vendidos nesses locais estão de acordo com os requisitos físico-químicos, mas fora dos padrões microbiológicos exigidos pela legislação brasileira, o que indica a falta de controle higiênico-sanitário desses produtos, apresentando inclusive, em alguns, a presença de bactérias patogênicas.

\section{REFERÊNCIAS}

ABREU, E. S.; MEDEIROS, S. F.; SANTOS, D. A. Análise microbiológica de mãos de manipuladores de alimentos do município de Santo André. Revista Univap, v. 17, n. 30, 2011. DOI: 10.18066/revunivap.v17i30.24

ABREU, S. C.; CABRAL, M. M. W. Análises microbiológicas de placas de corte de madeira para identificação de bactérias pertencentes ao grupo das Enterobacteriaceae. Investigação - Revista Científica da Universidade de Franca, v. 5, n. 1-6, p. 132-138, 2005. DOI: 10.26843/investigacao.v5i1-6.205

ALMEIDA, A. C. et al. Caracterização da produção de queijo artesanal na região de
Montes Claros, norte de Minas Gerais. Acta Veterinaria Brasilica, v. 6, n. 4, p. 312-320, 2012.

ALMEIDA FILHO, E. S.; NADER FILHO, A. Ocorrência de Staphylococcus aureus em queijo tipo "Frescal". Revista de Saúde Pública, v. 34, n. 6, p. 578-580, 2000.

ALVES, V. O. Avaliação higiênico-sanitária de amostras de queijos Minas Frescal artesanais comercializados em feiras livres da cidade de Volta Redonda RJ e suscetibilidade antimicrobiana das estirpes patogênicas isoladas. 2013 134 f. Dissertação (Mestrado em Higiene Veterinária e Processamento Tecnológico de Produtos de Origem Animal) - Faculdade de Medicina Veterinária, Universidade Federal Fluminense, Niterói, 2013.

AMORIM, A. L. et al. Avaliação da qualidade microbiológica de queijos do tipo Minas Padrão de produção industrial, artesanal e informal. Revista do Instituto Adolfo Lutz, v. 73, n. 4 p. 364-367, 2014. DOI: 10.18241/0073-98552014731628

APOLINÁRIO, T. C.; SANTOS, G. S.; LAVORATO, J. A. A. Avaliação da qualidade microbiológica do queijo Minas Frescal produzido por laticínios do estado de Minas Gerais. Revista do Instituto de Laticínios Cândido Tostes, v. 69, n. 6, p. 433-442, 2014. DOI: $10.14295 / 2238-6416 . v 69 i 6.290$

BANNERMAN, T. L. Staphylococcus, Micrococcus and other catalase-positive cocci. In: MURRAY, P. R.; BARON, E. J.; JORGENSEN, J. H.; PFALLER, M. A.; YOLKEN, R. H. (ed.). Manual of Clinical Microbiology. 8. ed. Washington: American Society for Microbiology, 2003. p. 384-404.

BARBOSA, P. F; SIQUEIRA, L. A.; 
MATIAS, A. E. B. Análises microbiológicas e físico-químicas de queijos Minas frescal comercializados em feiras livres. REVISA, v. 8 , n. 2 p. $52-147,2019$.

BORGES, M; F. et al. Microrganismos patogênicos e indicadores em queijo de Coalho produzido no estado do Ceará, Brasil. Boletim Centro de Pesquisa de Processamento de Alimentos, v. 21, n. 1, p. 31-40, 2003. DOI: 10.5380/cep.v21i1.1146

BRASIL. Ministério da Agricultura, Pecuária e Abastecimento. Instrução Normativa $n^{\circ} 4$, de 01 de março de 2004. Altera a Portaria $n^{\circ}$ 352 de 04 de setembro de 1997, que aprova o Regulamento Técnico para fixação de Identidade e Qualidade do Queijo Minas Frescal. Diário Oficial da União: seção 1, Brasília, DF, n. 44, p. 5, 05 mar. 2004a.

BRASIL. Ministério da Agricultura, Pecuária e Abastecimento. Instrução Normativa $\mathrm{n}^{\mathrm{o}}$ 66, de 21 de julho de 2020. Dispõe sobre a identidade e os requisitos de qualidade que deve apresentar o produto denominado queijo Minas Padrão. Diário Oficial da União: seção 1, Brasília, DF, n.140, p. 4, 23 jul 2020.

BRASIL. Ministério da Agricultura, do Abastecimento e da Reforma Agrária. Portaria no 146, de 7 de março de 1996. Aprova os Regulamentos Técnicos de Identidade e Qualidade dos Produtos Lácteos. Diário Oficial da República Federativa do Brasil: seção 1, Brasília, DF, n. 48, p. 3977 , 11 mar. 1996.

BRASIL. Ministério da Agricultura e do Abastecimento. Portaria $n^{\circ} 352$, de 4 de setembro de 1997. Regulamento Técnico para Fixação de Identidade e Qualidade de Queijo Minas Frescal. Diário Oficial da República Federativa do Brasil: seção 1, Brasília, DF, n. 172 , p. 19684,08 set. 1997.
BRASIL. Ministério da Saúde. Agência Nacional de Vigilância Sanitária. Portaria $n^{\circ}$ 1428, de 26 de novembro de 1993. Aprova o Regulamento Técnico para Inspeção Sanitária de Alimentos, as Diretrizes para o Estabelecimento de Boas Práticas de Produção e de Prestação de Serviços na Área de Alimentos e o Regulamento Técnico para o Estabelecimento de Padrão de Identidade e Qualidade (PIQs) para Serviços e Produtos na Área de Alimentos. Diário Oficial da União: seção 1, Brasília, DF, n. 229, p. 18414, 02 dez 1993.

BRASIL. Ministério da Saúde. Agência Nacional de Vigilância Sanitária. Resolução RDC n ${ }^{\circ} 12$, de 2 de janeiro de 2001. Aprova o Regulamento Técnico sobre Padrões Microbiológicos para Alimentos. Diário Oficial da União: seção 1, Brasília, DF, n. 7, p. 45,10 jan. 2001 .

BRASIL. Ministério da Saúde. Agência Nacional de Vigilância Sanitária. Resolução RDC n ${ }^{\circ} 216$, de 15 de setembro de 2004. Dispõe sobre Regulamento Técnico de Boas Práticas para Serviços de Alimentação. Diário Oficial da União: seção 1, Brasília, DF, n. 179, p. 25,16 set 2004 b.

BURITI, F. C. A.; ROCHA, J. S.; SAAD, S. M. I. Incorporation of Lactobacillus acidophilus in Minas fresh cheese and implicatons for textural and sensorial properties during storage. International Dairy Journal, v. 15, n. 12 , p. $1279-1288,2005$. DOI: $10.1016 /$ j. idairyj.2004.12.011

BUYSER, M. L.; DUFOUR, B.; MAIRE, M.; LAFARGE, V. Implication of milk and milk products in food-borne diseases in France and different industrialised countries. International Journal of Food Microbiology, v. 67, n. 1-2, p. 1-17, 2001. DOI: $10.1016 / \mathrm{s} 0168-1605(01) 00443-3$. 
CACCAMO, M. et al. Measurement of gas holes and mechanical openness in cheese by image analysis. American Dairy Science Association, v. 87, n. 3, p. 739-748, 2004. DOI: $10.3168 /$ jds.S0022-0302(04)73217-8

CAMPO GRANDE. Lei ${ }^{\circ} 223$, de 14 de janeiro de 2014. Dispõe sobre as feiras livres no município de Campo Grande e dá outras providências. Diário Oficial de Campo Grande, n. 3934, parte II - Poder Legislativo, p. 14-16, 16 jan 2014.

CAMPO GRANDE. Secretaria de Municipal de Cultura e Turismo. Mercado Municipal Antônio Valente. Campo Grande, [20-?]. Disponível em: www.campogrande.ms.gov. br/sectur/artigos/mercado-municipal-antoniovalente/ Acesso em: 23 jun. 2019.

CARvalho, C. T. et al. Condições higiênico-sanitárias da carne bovina vendida em feiras livres de Natal, Rio Grande do Norte. Revista de Nutrição e Vigilância em Saúde, v. 3, n. 3, p. 121-128, 2017. DOI: 10.17648/nutrivisa-vol-3-num-3-d

CASTRO, J. O. et al. Uso de ardósia na construção de celas de maternidade: I Efeito sobre o ambiente e comportamento de suínos. Engenharia Agrícola, v. 31, n. 3, p. 458-467, 2011. DOI: 10.1590/S010069162011000300006 .

CAVAlCANTI, C. R. et al. Avaliação e diagnóstico das condições de comercialização de alimentos nas feiras livres no estado da Paraíba. Arquivos de Ciências Veterinárias e Zoologia da UNIPAR, v. 17, n. 3, p. 165-170, 2014. DOI: 10.25110 /arqvet.v17i3.4939

DIAS, B. F. et al. Qualidade microbiológica e físico-química de queijo Minas frescal artesanal e industrial. Revista de Agricultura Neotropical, v. 3, n. 3, p. 57-64, 2016. DOI: 10.32404/rean.v3i3.1211
FAVA, L. W. et al. Características de queijos artesanais tipo Colonial comercializados em uma feira agropecuária. Acta Scientiae Veterinariae, v. 40, n. 4, pub. 1084, 2012.

FERREIRA, R. M. et al. Quantificação de coliformes totais e termotolerantes em queijo Minas Frescal artesanal. PUBVET, v. 5, n. 5, art. 1022, 2011.

FRANCO, B. D. G. M.; LANDGRAF, M. Microbiologia de Alimentos. 2. ed. São Paulo: Atheneu, 2008. 196 p.

FREIRE, J. L.; SILVA, B. B.; SOUZA, A. S. Aspectos econômicos e higiênico-sanitários da comercialização do pescado no município de Bragança (PA). Biota Amazônia, v. 1, n. 2, p. 17-28, 2011.

FURTADO, M. M. Principais Problemas dos Queijos. São Paulo: Setembro Editora, 2017.

GOnTiJO, C. M.; BRAnCO, A. B. A. Avaliação microbiológica do leite pasteurizado e de derivados do leite no Distrito Federal Janeiro/1990 a dezembro/1996. Revista Saúde Distrito Federal, n. 9, p. 27-32, 1998.

HOBBS, B. C.; ROBERTS, D. Toxinfecções e Controle Higiênico-Sanitário de Alimentos. São Paulo: Varela, 1999. 376 p.

HOLANDA, M. A. et al. Avaliação das condições higiênico-sanitárias das feiras livres de comercialização de peixe na cidade de Caxias-MA. Acta Tecnológica, v. 8, n. 2, p. $30-35,2013$. DOI: $10.35818 /$ acta.v8i2.101

INMETRO - INSTITUTO NACIONAL DE METRologia. Programa de Análise de Produtos - Queijos Tipo Minas Frescal e Padrão. 2006. Disponível em: http://www. inmetro.gov.br/consumidor/produtos/queijo Minas.asp. Acesso em: 26 jun 2020. 
KORNACKI, J. L.; GURTLER, J. B.; STAWICK, B. A. Enterobacteriaceae, coliforms, and Escherichia coli as quality and safety indicators. In: SALFINGER, Y.; TORTORELLO, M. L. (ed.). Compendium of Methods for the Microbiological Examination of Foods. 5. ed. Washington: American Public Health Association (APHA), 2015. cap. 9, p. 103-120.

KOUSTA, M. et al. Prevalence and sources of cheese contamination with pathogens at farm and processing levels. Food Control, v. 21 , n. 6 , p. $805-815$, 2010. DOI: $10.1016 /$ j. foodcont.2009.11.015

LUNDGREN, P. U. et al. Perfil da qualidade higiênico-sanitária da carne bovina comercializada em feiras livres e mercados públicos de João Pessoa/PB-Brasil. Alimentos e Nutrição, v. 20, n. 1, p. 113-119, 2009.

MASCARENHAS, G.; DOLZANI, M. Feira livre: Territorialidade popular e cultura na metrópole contemporânea. Ateliê Geográfico, v. 2, n. 2, p. 72-87, 2008.

MELO, F. D. et al. Avaliação da inocuidade e qualidade microbiológica do queijo artesanal serrano e sua relação com as variáveis físicoquímicas e o período de maturação. Acta Scientiae Veterinariae, v. 41, pub. 1152, 2013.

PINTO, L. F. et al. Avaliação das condições higiênico-sanitárias das bancas de comercialização de peixe no mercado de peixe de Teresina-PI. In: CONGRESSO NORTE NORDESTE DE PESQUISA E INOVAÇÃO, 7., 2012, Palmas. Anais [...]. Palmas: CONNEPI, 2012. Disponível em: http://bit.ly/1ohCxnV. Acesso em: 01 fev. 2020.

PORTO, M. A. L. et al. Coliformes em água de abastecimento de lojas fast-food da região metropolitana de Recife (PE, Brasil). Ciência e Saúde Coletiva, v. 16, n. 5, p. 2653-2658, 2011. DOI: $10.1590 / \mathrm{S} 1413-81232011000500035$

PRADELLA, S. T.; BASSO, C. Qualidade higiênico sanitária em feiras livres da cidade de Santa Maria-RS. Higiene Alimentar, v. 29, n. 242/243, p. $60-65,2015$.

RAIMUNDO, D. C. Listeria monocytogenes em queijo Minas meia cura: Análise quantitativa, qualitativa e perfil molecular das cepas isoladas. 2013. 52 f. Tese (Doutorado em Epidemiologia Experimental Aplicada às Zoonoses) - Faculdade de Medicina Veterinária e Zootecnia, Universidade de São Paulo, São Paulo, 2013.

REZENDE, P. H. L. et al. Aspectos sanitários do queijo Minas artesanal comercializado em feiras livres. Revista do Instituto de Laticínios Cândido Tostes, v. 65, n. 377, p. 36-42, 2010.

RICARDO, N. et al. Análise físicoquímica de queijos Minas frescal artesanais e industrializados comercializados em Londrina-PR. Revista Brasileira de Pesquisa em Alimentos, v. 2, n. 2, p. 89-95, 2011.

ROCHA, J. S.; BURITI, F. C. A.; SAAD, S. M. I. Condições de processamento e comercialização de queijo-de-Minas frescal. Arquivo Brasileiro de Medicina Veterinária e Zootecnia, v. 58, n. 2, p. 263-272, 2006.

SILVA, F. T. Queijo Minas Frescal. Brasília: Embrapa Informação Tecnológica, 2005. 50 p.

Silva, M.; MATte, G.; MATTE, M. Aspectos sanitários da comercialização de pescado em feiras livres da cidade de São Paulo, SP/Brasil. Revista do Instituto Adolf Lutz, v. 67, n. 3, p. 208-2014, 2008.

SOUSA, T. L. et al. Avaliação físico-química 
e microbiológica de queijo Minas frescal comercializado em feiras livres de Goiás. Alimentos: Ciência, Tecnologia e Meio Ambiente, v. 1, n. 5, p. 120-132, 2020.

SOUZA, I. et al. Qualidade microbiológica de queijo Minas frescal comercializado na zona da mata mineira. Revista do Instituto de Laticínios Cândido Tostes, v. 72, n. 3, p. 152-162, 2017. DOI: 10.14295/2238-6416. v72i3.598

TINOCO, B. O. W. et al. Avaliação das condições higiênico-sanitárias dos manipuladores de alimentos das barracas da feira livre de Seropédica, RJ. In:
C ONGRESSO BR A S ILEIRO DE ECONOMIA DOMÉSTICA, 20,, 2009, Fortaleza. Anais [...]. Fortaleza: UFC, 2009. Disponível em: http://www.xxcbed.ufc.br/ arqs/gt6/gt6_25.pdf. Acesso em: 06 jul 2020.

ZANDONADI, R. P. et al. Atitudes de risco do consumidor em restaurantes de auto-serviço. Revista de Nutrição, v. 20, n. 1 , p. $19-26,2007$. DOI: $10.1590 / \mathrm{S} 1415-$ 52732007000100002 .

ZENEBON, O.; PASCUET, N. S.; TIGLEA, P. (coord.). Métodos físico-químicos para análise de alimentos. 4. ed., 1. ed. digital. São Paulo: Instituto Adolfo Lutz, 2008.1020 p. 